\title{
Tuning the Thermal Conductivity of the Amorphous PAA Polymer via Vapor-Phase Infiltration
}

\author{
Viet Phuong Nguyen, Duckjong Kim, and Seung-Mo Lee*
}

Cite This: ACS Omega 2021, 6, 29054-29059

Read Online

ABSTRACT: The thermal properties of the polymer, together with mechanical stability, have been one of the key engineering factors to be considered for various applications. Here, we engineered the thermal conductivity of the amorphous poly(acrylic acid) (PAA) polymer by vapor-phase infiltration (VPI), which has usually occurred during the atomic layer deposition process. We observed that the VPI causes metal infiltration (e.g., $\mathrm{Al}$ and $\mathrm{Zn}$ ) into the amorphous PAA polymer, which noticeably increases the thermal conductivity of the PAA polymer. From spectroscopy analysis and density functional theory simulations, we found that the carboxyl groups $(-\mathrm{COOH})$ in PAA are notably modified and the bonding states of carbon and oxygen are significantly altered by the infiltrated metal. The newly formed Al-mediated bonds likely provide continuous phonon propagation pathways, thereby enhancing the thermal conductance. We believe that VPI could be a simple and useful way to engineer the thermal properties of various polymeric materials.

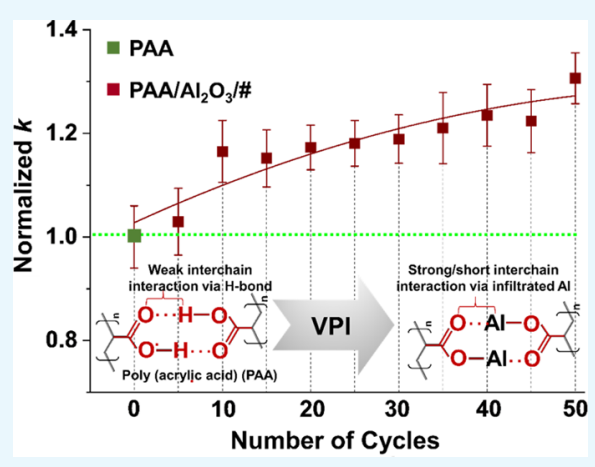

\section{INTRODUCTION}

The thermal conductivity $(k)$ of the polymer, unlike common thermal management materials such as metals and ceramics, is generally poor. Nevertheless, its incommensurable advantages (such as lightweight, low cost, and processability) make the polymer the material of choice for various heat-involved applications. ${ }^{1}$ The mechanism regarding thermal transport in the polymer has been long investigated. ${ }^{2,3}$ Phonon (i.e., quantized lattice vibration wave) is the central thermal energy carrier in the polymer, which can travel linearly along a continuous path of chemical bonds. Considering the plane wave nature of phonons, propagation of phonons is strongly affected by the curvature and the sequence of the polymer chains. Chain entanglement, poor chain packing, and weak interchain interaction (i.e., van der Waals bond and hydrogen bond) are lethal factors to hinder the phonon propagation in the polymer. ${ }^{4}$ In the literature, the filler-free approach (such as changing the degree of crystallinity, ${ }^{3,5}$ the molecular bond strength, ${ }^{6}$ the degree of cross-linking, ${ }^{7}$ or the chain alignment ${ }^{8}$ ) was reported to be promising to increase the thermal conductivity of the polymer. Cross-links are known to form efficient heat conduction networks and pathways by connecting polymer chains with strong covalent bonds. ${ }^{9}$ Experimental and theoretical works have already demonstrated that the increase in the cross-link leads to the higher thermal conductivity of the polymer, ${ }^{10-16}$ although the opposite results have also been reported. ${ }^{17,18}$ Therefore, proper modulation of the cross-links, without doubt, could be an effective filler-free approach to tailor the thermal conductivity of the polymer.

Here, we demonstrate that various transition metals could be infiltrated into the diverse polymers by the vapor-phase infiltration (VPI) phenomenon commonly occurred during the atomic layer deposition (ALD). ${ }^{19,20}$ For a proof of concept, we selected the amorphous poly(acrylic acid) (PAA) as a model polymer because it frequently undergoes notable conformational changes due to the hydrogen bonds between carboxylic groups $(-\mathrm{COOH}){ }^{21,22} \mathrm{We}$ applied $\mathrm{Al}$ or $\mathrm{Zn}$ VPI to the amorphous PAA using conventional $\mathrm{Al}_{2} \mathrm{O}_{3}$ or $\mathrm{ZnO}$ ALD processes. We observed a notable increase in the through-plane thermal conductivity of PAA after $\mathrm{Al}$ or $\mathrm{Zn}$ VPI ( $30 \%$ increase). To theoretically speculate the most probable changes in the molecular structure of PAA by VPI, density functional theory (DFT) simulation was performed. In addition, to experimentally detect the specific molecular structure changes, various spectroscopic measurements were carefully carried out and a thorough analysis of the collected data was followed. The obtained results from DFT simulations and spectroscopy analysis suggested that the infiltrated metals ( $\mathrm{Al}$ or $\mathrm{Zn}$ ) likely form metal-coordinated covalent bonds in the inter-/intramolecular chain of PAA where originally hydrogen bonds exist. It is believed that our molecular engineering route using the VPI phenomenon could be widely used for tuning the thermal conductivity of the common polymer.

Received: August 7, 2021

Accepted: October 11, 2021

Published: October 21, 2021 


\section{RESULTS AND DISCUSSION}

To fabricate thin films for thermal conductivity measurement, we dissolved PAA in deionized water, and the polymer solution was then spin-coated on a Si wafer, followed by annealing at 90 ${ }^{\circ} \mathrm{C}$ for $30 \mathrm{~min}$. Then, the prepared PAA samples with a thickness of $\sim 500 \mathrm{~nm}$ were transferred into the ALD chamber, where an $\mathrm{Al}_{2} \mathrm{O}_{3}$ or $\mathrm{ZnO}$ ALD process was carried out (Figure S1). Analyses using field emission scanning electron microscopy (FESEM) and atomic force microscopy (AFM) indicated that the change in the surface topology of PAA is less conspicuous before and after $\mathrm{Al}_{2} \mathrm{O}_{3}$ deposition (Figure $1 \mathrm{~A}, \mathrm{~B}$ ).
(A)

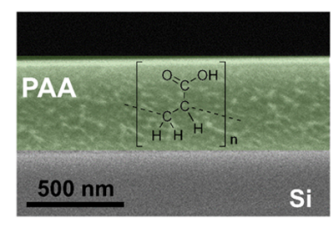

$10 \mu \mathrm{m}$

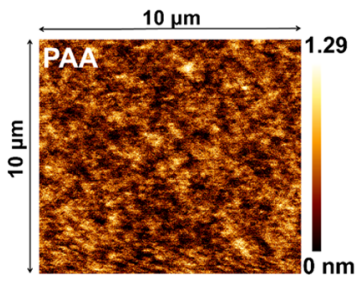

(B)
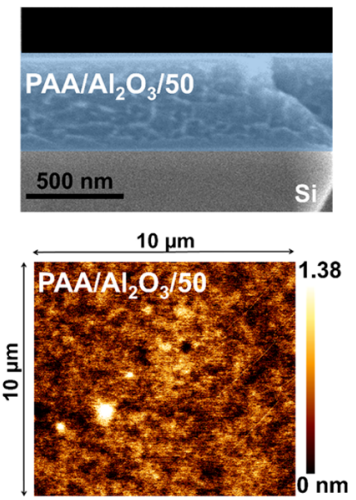

Figure 1. Change in the surface morphology of PAA before and after $\mathrm{Al}_{2} \mathrm{O}_{3}$ ALD. (A,B) SEM and AFM images of PAA and PAA $/ \mathrm{Al}_{2} \mathrm{O}_{3}$ / 50, respectively. PAA $/ \mathrm{Al}_{2} \mathrm{O}_{3} / 50$ indicates PAA with $\mathrm{Al}_{2} \mathrm{O}_{3}$ deposited by $50 \mathrm{Al}_{2} \mathrm{O}_{3} \mathrm{ALD}$ cycles (i.e., sample denotation: $\mathrm{PAA} / \mathrm{Al}_{2} \mathrm{O}_{3} / \#$, where \# is the number of $\mathrm{Al}_{2} \mathrm{O}_{3}$ ALD cycles).

To investigate the thermal properties of neat PAA and PAA/ $\mathrm{Al}_{2} \mathrm{O}_{3}$ /\# (\# denotes the number of ALD cycles), we performed thermal conductivity measurement using time domain thermoreflectance (TDTR) (Figure S2). ${ }^{23,24}$ A pump laser beam first heats the $\mathrm{Au}$ thin film $(\sim 240 \mathrm{~nm})$ on the sample, which was prepared before the TDTR because of its large thermoreflectance coefficient. As the heat propagates into the sample, the surface temperature decreases. A delayed probe laser beam is then reflected from the sample into the detector. The reflectance of the probe beam changes with the surface temperature (governed by the thermoreflectance coefficient), which is recorded with time. As compared to the neat PAA film $\left(k_{\perp, \mathrm{PAA}} \approx 0.32 \mathrm{~W} / \mathrm{mK}\right),{ }^{25}$ the $\mathrm{Al}_{2} \mathrm{O}_{3}$-deposited PAA (PAA/ $\left.\mathrm{Al}_{2} \mathrm{O}_{3} / \#\right)$ showed a gradual increase by a maximum of $\sim 30 \%$ in the through-plane thermal conductivity $\left(k_{\perp}\right)$ with ALD cycles (Figure 2). The $\mathrm{ZnO}$-deposited PAA exhibited a similar level of increase in thermal conductivity (Figure S3). For reference, $\mathrm{Al}_{2} \mathrm{O}_{3}$ and $\mathrm{ZnO}$ with a thickness of $\sim 500 \mathrm{~nm}$ were deposited on the $\mathrm{Si}$ wafer by $\mathrm{ALD}$, and the through-plane thermal conductivity was measured. The measured values for the pure $\mathrm{Al}_{2} \mathrm{O}_{3}$ and $\mathrm{ZnO}$ layers were $k_{\perp, \mathrm{Al}_{2} \mathrm{O}_{3}} \approx 1.69$ and $k_{\perp, \mathrm{ZnO}}$ $\approx 2.39 \mathrm{~W} / \mathrm{mK}$, respectively, which were much higher than that of the neat PAA. Therefore, the increase in the thermal conductivity of PAA was thought to be likely caused by the molecular structure change after ALD rather than the coating effect of ALD.

To validate the presumable molecular structure change of PAA after $\mathrm{Al}_{2} \mathrm{O}_{3} \mathrm{ALD}$, first X-ray photoelectron spectroscopy (XPS) analysis was performed. The XPS intensity is dependent mostly on surface concentrations rather than surface chemistry.

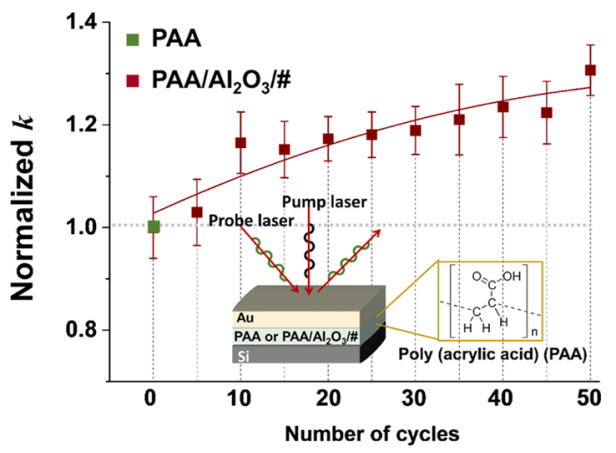

Figure 2. Change in the thermal conductivity of PAA before and after $\mathrm{Al}_{2} \mathrm{O}_{3} \mathrm{ALD}$. The increase in the through-plane thermal conductivity $\left(k_{\perp}\right)$ of the PAA $/ \mathrm{Al}_{2} \mathrm{O}_{3}$ films with different $\mathrm{Al}_{2} \mathrm{O}_{3} \mathrm{ALD}$ cycles. As compared to the neat PAA film, the $k_{\perp}$ of $\mathrm{PAA} / \mathrm{Al}_{2} \mathrm{O}_{3}$ was measured to gradually increase by a maximum of $\sim 30 \%$ with the ALD cycle.

Thus, XPS is known to provide good quantitative composition measurements. For this reason, XPS depth profiling has been performed by alternating sputter etching of the representative $\mathrm{PAA} / \mathrm{Al}_{2} \mathrm{O}_{3} / 50$ sample for quantitative analysis. Notable $\mathrm{Al}$ signals were detected on the surface as well as in the interior of $\mathrm{PAA} / \mathrm{Al}_{2} \mathrm{O}_{3} / 50$ (Figure 3A). The $\mathrm{Al}$ infiltration depth was found to be over $300 \mathrm{~nm}$. These results presented clear evidence that $\mathrm{Al}_{2} \mathrm{O}_{3}$ ALD leads to $\mathrm{Al}_{2} \mathrm{O}_{3}$ coating on the surface of PAA as well as $\mathrm{Al}$ infiltration into PAA by VPI. The infiltrated $\mathrm{Al}$ appeared to mostly interact with oxygen, as can be recognized from the pronounced changes in the $\mathrm{O} 1 \mathrm{~s}$ core scan spectra (Figure 3B). Three peaks centered at $\sim 529.7 \mathrm{eV}$ $(\mathrm{C}=\mathrm{O}), \sim 531.2 \mathrm{eV}(\mathrm{C}-\mathrm{O})$, and $\sim 532.4 \mathrm{eV}(\mathrm{C}-\mathrm{OH})$ were identified in the $\mathrm{O} 1 \mathrm{~s}$ signal of $\mathrm{PAA} / \mathrm{Al}_{2} \mathrm{O}_{3} / 50{ }^{26}$ These peaks displayed pronounced peak shifts, which indicated that serious changes in the molecular structure of PAA occur by Al VPI. The $\mathrm{O} 1 \mathrm{~s}$ spectrum of the $\mathrm{Al}_{2} \mathrm{O}_{3} / \mathrm{Si}$ surface was deconvoluted into two components consisting of the $\mathrm{O}-\mathrm{Al}-\mathrm{O}$ peak (red spectrum) centering at $530.8 \mathrm{eV}$ and $-\mathrm{OH} / \mathrm{AlOOH}$ peak (green spectrum) centering at about $531.6 \mathrm{eV}$ (Figure 3C). ${ }^{27}$ As compared to the $\mathrm{O} 1 \mathrm{~s}$ core scan spectrum of the neat PAA (PAA/Si) and $\mathrm{Al}_{2} \mathrm{O}_{3}\left(\mathrm{Al}_{2} \mathrm{O}_{3} / \mathrm{Si}\right)$ surface, the spectrum of the $\mathrm{PAA} / \mathrm{Al}_{2} \mathrm{O}_{3} / 50$ surface also exhibited significant differences. The $\mathrm{O}-\mathrm{Al}-\mathrm{O}$ peak showed a larger shift in comparison with the $\mathrm{OH} / \mathrm{AlOOH}$ peak. It implied that new bonds in the form of $\mathrm{X}-\mathrm{Al}-\mathrm{Y}$ likely are created in PAA after Al VPI. Considering that PAA has a carboxyl group $(-\mathrm{C}(=\mathrm{O}) \mathrm{OH}$, usually written as $-\mathrm{COOH}$ or $\left.\mathrm{CO}_{2} \mathrm{H}\right)$ consisting of a carbonyl group $(\mathrm{C}=\mathrm{O})$ with a hydroxyl group $(\mathrm{O}-\mathrm{H})$ attached to the same carbon atom, the observed change in the XPS O 1s spectra suggested that the infiltrated $\mathrm{Al}$ creates new bonds likely in the region of the carboxyl groups in PAA. Indeed, the FTIR (Fourier transform infrared spectroscopy) spectra of the carbonyl group $(\mathrm{C}=\mathrm{O})$ of PAA before and after Al VPI suggested that our supposition is highly feasible (Figure 3D). The FTIR spectra of carbonyl functional groups were deconvoluted into two components: hydrogen-bonded carbonyl groups $\left(\nu_{\mathrm{H}-\mathrm{C}=\mathrm{O}}=\right.$ $\left.\sim 1712 \mathrm{~cm}^{-1}\right)$ and free $\left(\nu_{\mathrm{F}-\mathrm{C}=\mathrm{O}}=\sim 1742 \mathrm{~cm}^{-1}\right)$ carbonyl groups. $^{28-30}$ The relative intensity of those two peaks (i.e., $\Gamma=$ $I_{\mathrm{H}-\mathrm{C}=\mathrm{O}} / I_{\mathrm{F}-\mathrm{C}=\mathrm{O}}$ ) gradually decreased, indicating that the concentration of the hydrogen-bonded carbonyl groups reduces presumably due to the Al-mediated new bonds. Besides, the peak of the hydrogen-bonded carbonyl groups red-shifted as the number of $\mathrm{Al}_{2} \mathrm{O}_{3} \mathrm{ALD}$ cycles increases. This 
(A)

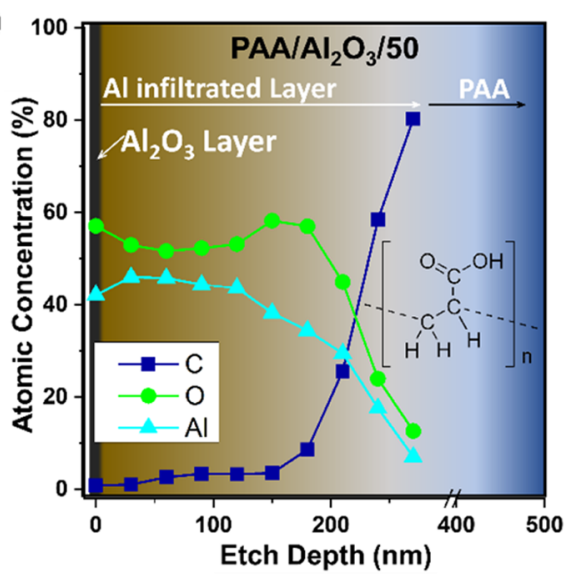

(C)

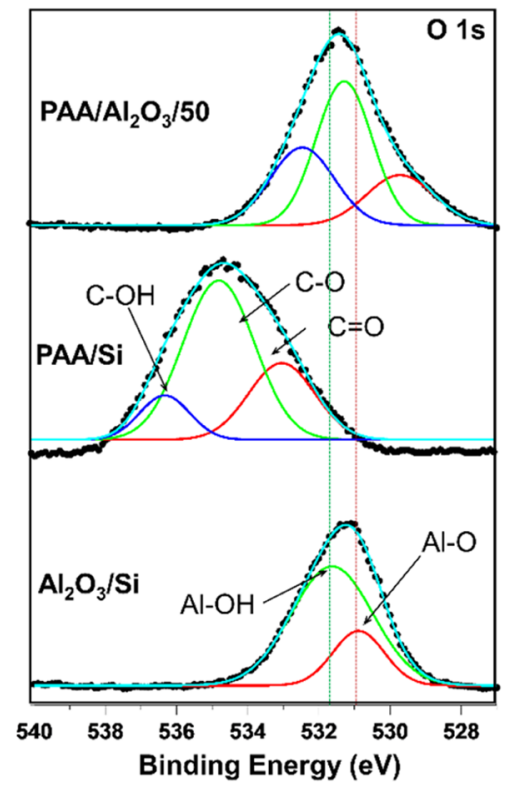

(B)

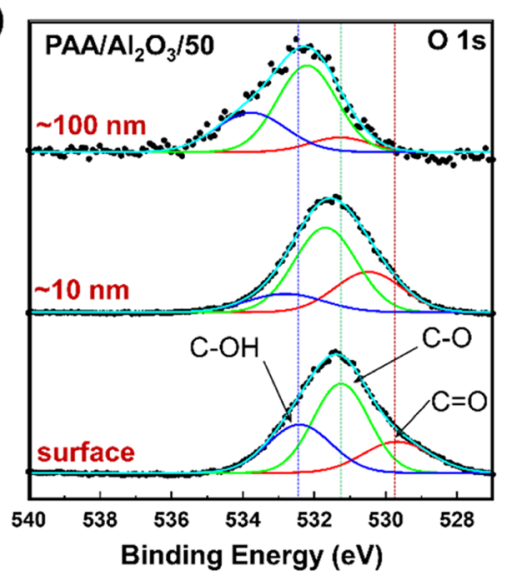

(D)

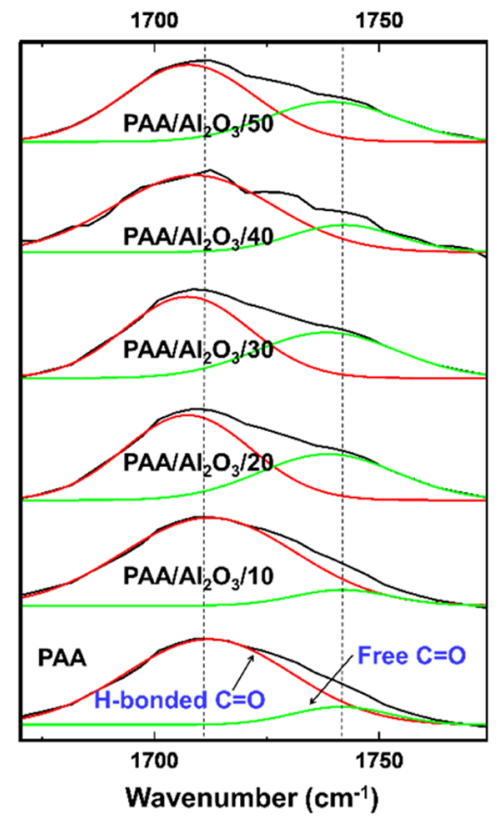

Figure 3. XPS and FTIR analyses of neat PAA and the $\mathrm{Al}_{2} \mathrm{O}_{3}$-deposited PAA. (A) XPS depth profile and (B) XPS O 1s spectra of the PAA/Al $\mathrm{O}_{3} /$ 50 sample with depth. (C) Comparative XPS O 1s spectra of $\mathrm{Al}_{2} \mathrm{O}_{3} / \mathrm{Si}, \mathrm{PAA} / \mathrm{Si}$, and $\mathrm{PAA} / \mathrm{Al}_{2} \mathrm{O}_{3} / 50$. (D) FTIR spectra of the PAA/Al $\mathrm{O}_{3} / \#$ sample with the number of ALD cycles. The peak was fitted by considering the following contributions: hydrogen-bonded $\mathrm{C}=\mathrm{O}$ and free $\mathrm{C}=\mathrm{O}$. See the text for a detailed discussion.

implied that the molecular structure change in PAA is proportional to the applied number of ALD cycles.

To further clarify the molecular structure change in PAA, DFT calculations were carried out. Based on a previous theoretical study, ${ }^{31}$ we selected the $\mathrm{COOH}$ group in PAA as the reaction center. The $\mathrm{OH}$ site in $\mathrm{COOH}$ is known to act as a hydrogen donor to trigger the ligand-exchange reaction with trimethylaluminum. The trimethylaluminum $\left[\mathrm{Al}\left(\mathrm{CH}_{3}\right)_{3}\right]$ (TMA) precursor was predicted to physically adsorb on PAA with an energy barrier of $-0.352 \mathrm{eV}$, resulting in a Lewis acidLewis base complex (Figure S4). It was found that in the transition state, a four-centered $\mathrm{Al}-\mathrm{O}-\mathrm{H}-\mathrm{C}$ configuration is temporarily created and followed by relocating the hydrogen atom of the $-\mathrm{OH}$ group to the $-\mathrm{CH}_{3}$ group of TMA, thereby forming the $\mathrm{Al}-\mathrm{O}-\mathrm{C}$ bond and gas-phase byproduct $\mathrm{CH}_{4}$. The energy barrier for this ligand-exchange process to reach the final state was calculated to be only $0.043 \mathrm{eV}$ (Figure 4A). It is believed that oxygen atoms could replace two remaining $\mathrm{CH}_{3}$ ligands in the $\mathrm{Al}$ atom because the PAA chains have plenty of $\mathrm{COOH}$ groups.
Experimentally, the XPS and FTIR analyses of PAA proved that $\mathrm{Al}_{2} \mathrm{O}_{3} \mathrm{ALD}$ on PAA induces $\mathrm{Al}$ infiltration by the VPI phenomenon, and the infiltrated $\mathrm{Al}$ likely forms new bonds in the hydrogen-bonded carbonyl groups. Theoretically, the DFT calculation supported that our assumption is thermodynamically as well as kinetically well within the bounds of possibility. Although the exact conformational change in the molecular structure of PAA after Al VPI remains to be further validated, XPS, FTIR, and DFT simulation results indicated that presumably the hydrogen bonds in the carbonyl groups are broken and transformed into new $\mathrm{Al}$-mediated bonds ( $\mathrm{C}-\mathrm{O}-$ $\mathrm{Al} \cdots \mathrm{O}=\mathrm{C}$ ) after $\mathrm{Al} \mathrm{VPI}$, as depicted in Figure 4B. Recent studies demonstrated that the engineering of the interchain bonds ${ }^{21}$ or the inter-/intramolecular structure at the molecular level $^{32,33}$ could appreciably increase the thermal conductivity of the polymer. In our case, the Al-mediated bonds are believed to prepare a continuous path for the phonon to propagate linearly, thereby notably increasing the overall thermal conductivity of PAA. A filler-based method has been still regarded as an effective approach to design a polymer with 
(A)

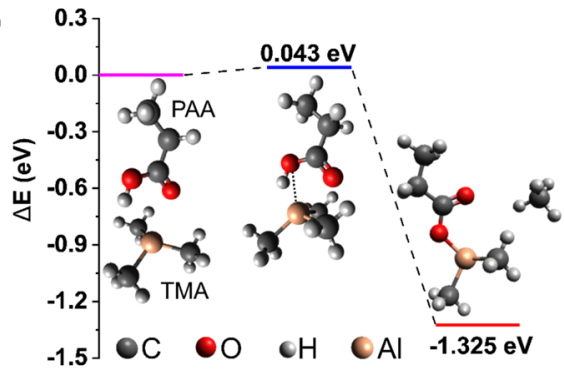

(B)
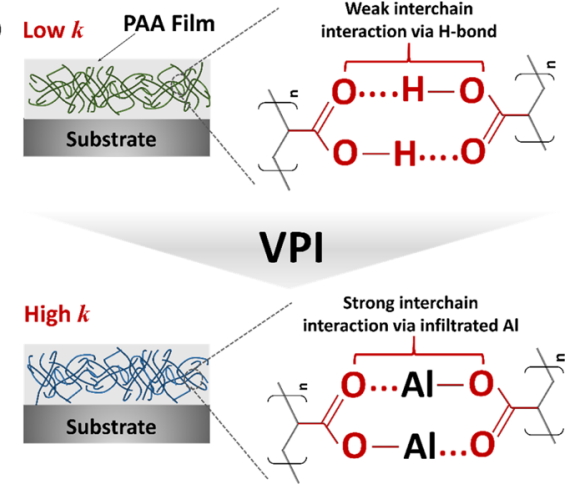

Figure 4. (A) Reaction path and predicted energetics for reactions of TMA and PAA on $-\mathrm{OH}$ site. (B) Tentative model to describe a change in the molecular structure of PAA before and after Al VPI. Based on the XPS and FTIR analysis results, we assumed that the hydrogen bonds in the carbonyl groups are transformed into $\mathrm{Al}$ mediated bonds $(\mathrm{C}-\mathrm{O}-\mathrm{Al} \cdots \mathrm{O}=\mathrm{C})$ after $\mathrm{Al}$ VPI. See the text for detail.

high thermal conductivity. However, the challenge is that a large number of fillers introduced for enhancing thermal conductivity usually tend to lead to unwanted changes in important characteristics such as optical, electrical, and mechanical properties. What is worse, the fillers cause an increase in cost as well as weight and a loss of easy processability. ${ }^{34,35}$ As opposed to the filler-based method, our VPI is a simple post-processing method to raise the thermal conductivity of the pure polymer to a higher level. It is strongly believed that our VPI-based method could be applied, regardless of the sort of the polymer. Of course, the resulting properties would be dependent on the microstructure and crystallinity of the employed polymers and could not be necessarily altered positively. Nevertheless, the VPI approach is thought to be well worth trying for tuning the various physical properties of the polymers including thermal properties.

\section{CONCLUDING REMARKS}

We demonstrated that the metal oxide ALD on the PAA polymer leads to the VPI phenomenon, and the resulting metal-infiltrated PAA shows a sharp improvement in the thermal property. The through-plane thermal conductivity of the Al- or Zn-infiltrated PAA was found to increase around $30 \%$ as compared to the neat PAA. From experimental spectroscopy analysis and theoretical DFT calculations, we found that the infiltrated $\mathrm{Al}$ atoms form new bonds likely in the hydrogen bonding region between carbonyl groups in the PAA chains, which build a continuous path for the phonon to travel freely. We strongly believe that the thermal conductivity can be further markedly increased by proper selection of the metals and rigorous optimization processes. Because the VPI is a common phenomenon easily occurring in various organic materials and the current ALD tool offers a broad selection of metal precursors, our method is thought to be widely applicable in the field of polymer-based thermal management materials.

\section{EXPERIMENTAL SECTION}

Sample Preparation. The powders of PAA (SigmaAldrich) were first poured into DI water and then stirred at $60{ }^{\circ} \mathrm{C}$ to form the PAA solution such that the concentration is around $5 \mathrm{wt} \%$. Then, the transparent PAA solution was spincoated on the silicon substrate $(3000 \mathrm{rpm}$ for $300 \mathrm{~s})$. Before that, the silicon wafer was cleaned by sonication with IPA, acetone, and water, followed by the oxygen plasma treatment for $3 \mathrm{~min}$ for each. The PAA-coated silicon substrate was annealed at $90{ }^{\circ} \mathrm{C}$ for about $30 \mathrm{~min}$ before $\mathrm{Al}_{2} \mathrm{O}_{3}$ and $\mathrm{ZnO}$ ALD. The thickness of the spin-coated PAA was multiply measured by spectroscopic ellipsometry (M-2000, J.A. Woollam).

VPI Using ALD. The samples were processed with $\mathrm{Al}_{2} \mathrm{O}_{3}$ and ZnO ALD (Cambridge NanoTech, Savannah 100) with a $\mathrm{N}_{2}$ flow of $20 \mathrm{sccm}$. The $\mathrm{Al}_{2} \mathrm{O}_{3}$ and $\mathrm{ZnO}$ ALD $\left(70{ }^{\circ} \mathrm{C}\right.$ and $\sim 0.1$ torr) was performed using two precursors of TMA (Sigma-Aldrich)/water and diethylzinc (DEZ, Sigma-Aldrich)/ water, respectively, for a various number of cycles from 5 to 50 . The $\mathrm{Al}_{2} \mathrm{O}_{3}$ ALD condition was set in the exposure mode with $0.015 \mathrm{~s}$ pulse $/ 40 \mathrm{~s}$ exposure $/ 60 \mathrm{~s}$ purge of TMA and $0.1 \mathrm{~s}$ pulse/40 s exposure/60 s purge of $\mathrm{H}_{2} \mathrm{O}$ in each ALD cycle. In the case of $\mathrm{ZnO} A L D$, the condition was set with $0.02 \mathrm{~s}$ pulse/ $40 \mathrm{~s}$ exposure/60 s purge of DEZ and $0.1 \mathrm{~s}$ pulse/40 $\mathrm{s}$ exposure/60 s purge of $\mathrm{H}_{2} \mathrm{O}$ in each ALD cycle. Si substrates were also loaded into the ALD chamber for reference. The thicknesses of the deposited $\mathrm{Al}_{2} \mathrm{O}_{3}$ and $\mathrm{ZnO}$ films were measured by ellipsometry (M-2000, J.A. Woollam). The growth rate of $\mathrm{Al}_{2} \mathrm{O}_{3}$ and $\mathrm{ZnO}$ on $\mathrm{Si}$ substrates was $\sim 1.0$ and $\sim 1.5 \AA$ /cycle, respectively.

Characterization. AFM (AFM JPK NanoWizard II) and FESEM (JSM-700F, JEOL) were used to analyze the surface morphology of the samples and measure the thickness of the PAA layer. XPS study was performed using an $\mathrm{Al} \mathrm{K} \alpha \mathrm{X}$-ray source (MultiLab 2000, Thermo) with a spot size of $0.5 \mu \mathrm{m}^{2}$. FTIR spectra were obtained using a Thermo Scientific Nicolet 6700 spectrometer.

Thermal Conductivity Measurement. After finishing metal infiltration by ALD processes, $\mathrm{Au}$ ( $240 \mathrm{~nm}$ in thickness) as a metal transducer layer was deposited on the raw PAA and the metal-infiltrated PAA polymer films by magnetron sputtering equipment. To measure the thermal conductivity of the samples, we used a TDTR measurement setup (Transometer thermoreflectance metrology system, TMX Scientific) at a magnification of 20 times (objective lens) and a laser energy of $2.7 \mu \mathrm{J}$ with a probe power of $5.5 \mathrm{~mW}$. A pump laser beam first heats the sample surface. As the heat propagates into the material, the surface temperature decreases. A delayed probe laser beam is then reflected from the sample into the detector. The reflectance of the probe beam changes with the surface temperature (governed by the thermoreflectance coefficient) and thus records the surface temperature decay as time. The data was collected after recording for $10,000 \mathrm{~s}$. The measured thermoreflectance signals are then fitted to a standard heat conduction model considering the $\mathrm{Au}$ transducer, the polymer film, and the interface in-between. For a single through-plane conductivity value, at least five identical samples were prepared and more 
than 10 measurements were carefully conducted before the calculation of average and standard deviation.

Theoretical Calculation. DFT calculations of reaction energies were carried out using the ORCA v4.2.1 package. ${ }^{36} \mathrm{~A}$ def2-SVP basis set was used for all atoms. ${ }^{37}$ The B3LYP ${ }^{38}$ hybrid functional with the $\mathrm{D} 3^{39,40}$ dispersion correction was employed for geometry optimization. All atoms were allowed to relax during optimization. The RIJCOSX approximation ${ }^{41}$ was applied to speed up the self-consistent field step of all calculations. Visualization of atoms and bonds was done using Avogadro software.

\section{ASSOCIATED CONTENT}

\section{SI Supporting Information}

The Supporting Information is available free of charge at https://pubs.acs.org/doi/10.1021/acsomega.1c04233.

Schematic diagram of the experimental procedure; TDTR measurement; increase in the through-plane thermal conductivity $\left(k_{\perp}\right)$ of $\mathrm{PAA} / \mathrm{ZnO}$ films with different $\mathrm{ZnO}$ ALD cycles; and optimized adsorption state for TMA on the $\mathrm{COOH}$ group of PAA (PDF)

\section{AUTHOR INFORMATION}

\section{Corresponding Author}

Seung-Mo Lee - Department of Nanomechanics, Korea Institute of Machinery and Materials (KIMM), Daejeon 34103, South Korea; Nano Mechatronics, Korea University of Science and Technology (UST), Daejeon 34113, South Korea; (1) orcid.org/0000-0003-0732-4473;

Email: sm.lee@kimm.re.kr

\section{Authors}

Viet Phuong Nguyen - Department of Nanomechanics, Korea Institute of Machinery and Materials (KIMM), Daejeon 34103, South Korea; Nano Mechatronics, Korea University of Science and Technology (UST), Daejeon 34113, South Korea; (1) orcid.org/0000-0002-7727-2499

Duckjong Kim - Department of Mechanical Engineering, Gyeongsang National University, Jinju 52828, South Korea

Complete contact information is available at:

https://pubs.acs.org/10.1021/acsomega.1c04233

\section{Notes}

The authors declare no competing financial interest.

\section{ACKNOWLEDGMENTS}

We would like to acknowledge the financial support from the internal research program of Korea Institute of Machinery and Materials (NK230D), the Global Frontier Project (CAMMNo. 2014063701 and 2014063700), and the National Research Foundation of Korea (NRF) grant funded by the Korea government (MSIT) (no. 2021R1A2C2004207). We would like to thank Nguyen Quy Dat for his experimental support.

\section{REFERENCES}

(1) Chen, H.; Ginzburg, V. V.; Yang, J.; Yang, Y.; Liu, W.; Huang, Y.; Du, L.; Chen, B. Thermal conductivity of polymer-based composites: fundamentals and applications. Prog. Polym. Sci. 2016, $59,41-85$.

(2) Choy, C. L. Thermal conductivity of polymers. Polymer 1977, $18,984-1004$.

(3) Choy, C. L.; Chen, F. C.; Luk, W. H. Thermal conductivity of oriented crystalline polymers. J. Polym. Sci. 1980, 18, 1187-1207.
(4) Henry, A. Thermal transport in polymers. Annu. Rev. Heat Transfer 2014, 17, 485-520.

(5) Choy, C. L.; Wong, Y. W.; Yang, G. W.; Kanamoto, T. Elastic modulus and thermal conductivity of ultradrawn polyethylene. $J$. Polym. Sci. 1999, 37, 3359-3367.

(6) O’Brien, P. J.; Shenogin, S.; Liu, J.; Chow, P. K.; Laurencin, D.; Mutin, P. H.; Yamaguchi, M.; Keblinski, P.; Ramanath, G. Bondinginduced thermal conductance enhancement at inorganic heterointerfaces using nanomolecular monolayers. Nat. Mater. 2013, 12, $118-122$.

(7) Yamamoto, O.; Kambe, H. Thermal conductivity of cross-linked polymers-comparison between measured and calculated thermal conductivities. Polym. J. 1971, 2, 623-628.

(8) Shen, S.; Henry, A.; Tong, J.; Zheng, R.; Chen, G. Polyethylene nanofibres with very high thermal conductivities. Nat. Nanotechnol. 2010, 5, 251-255.

(9) Huang, C.; Qian, X.; Yang, R. Thermal conductivity of polymers and polymer nanocomposites. Mater. Sci. Eng., R 2018, 132, 1-22.

(10) Wei, X.; Luo, T. Role of Ionization in Thermal Transport of Solid Polyelectrolytes. J. Phys. Chem. C 2019, 123, 12659-12665.

(11) Huo, R.; Zhang, Z.; Athir, N.; Fan, Y.; Liu, J.; Shi, L. Designing High Thermal Conductivity of Cross-Linked Epoxy Resin via Molecular Dynamics Simulations. Phys. Chem. Chem. Phys. 2020, 22, 19735-19745.

(12) Mukherji, D.; Singh, M. K. Tuning thermal transport in highly cross-linked polymers by bond-induced void engineering. Phys. Rev. Mater. 2021, 5, 025602.

(13) Lv, G.; Soman, B.; Shan, N.; Evans, C. M.; Cahill, D. G. Effect of Linker Length and Temperature on the Thermal Conductivity of Ethylene Dynamic Networks. ACS Macro Lett. 2021, 10, 1088-1093.

(14) Tonpheng, B.; Yu, J.; Andersson, O. Effects of cross-links, pressure and temperature on the thermal properties and glass transition behaviour of polybutadiene. Phys. Chem. Chem. Phys. 2011, 13, 15047-15054.

(15) Kikugawa, G.; Desai, T. G.; Keblinski, P.; Ohara, T. Effect of crosslink formation on heat conduction in amorphous polymers. $J$. Appl. Phys. 2013, 114, 034302.

(16) Xiong, X.; Yang, M.; Liu, C.; Li, X.; Tang, D. Thermal conductivity of cross-linked polyethylene from molecular dynamics simulation. J. Appl. Phys. 2017, 122, 035104.

(17) Ni, B.; Watanabe, T.; Phillpot, S. R. Thermal transport in polyethylene and at polyethylene-diamond interfaces investigated using molecular dynamics simulation. J. Phys.: Condens. Matter 2009, 21, 084219.

(18) Yu, S.; Park, C.; Hong, S. M.; Koo, C. M. Thermal conduction behaviors of chemically cross-linked high-density polyethylenes. Thermochim. Acta 2014, 583, 67-71.

(19) Lee, S.-M.; Pippel, E.; Gösele, U.; Dresbach, C.; Qin, Y.; Chandran, C. V.; Bräuniger, T.; Hause, G.; Knez, M. Greatly increased toughness of infiltrated spider silk. Science 2009, 324, 488492.

(20) Lee, S.-M.; Ischenko, V.; Pippel, E.; Masic, A.; Moutanabbir, O.; Fratzl, P.; Knez, M. An alternative route towards metal-polymer hybrid materials prepared by vapor-phase processing. Adv. Funct. Mater. 2011, 21, 3047-3055.

(21) Kim, G.-H.; Lee, D.; Shanker, A.; Shao, L.; Kwon, M. S.; Gidley, D.; Kim, J.; Pipe, K. P. High thermal conductivity in amorphous polymer blends by engineered interchain interactions. Nat. Mater. 2015, 14, 295-300.

(22) Xie, X.; Li, D.; Tsai, T.-H.; Liu, J.; Braun, P. V.; Cahill, D. G. Thermal conductivity, heat capacity, and elastic constants of watersoluble polymers and polymer blends. Macromolecules 2016, 49, 972978.

(23) Cahill, D. G.; Ford, W. K.; Goodson, K. E.; Mahan, G. D.; Majumdar, A.; Maris, H. J.; Merlin, R.; Phillpot, S. R. Nanoscale thermal transport. J. Appl. Phys. 2003, 93, 793-818.

(24) Schmidt, A. J.; Chen, X.; Chen, G. Pulse accumulation, radial heat conduction, and anisotropic thermal conductivity in pump-probe transient thermoreflectance. Rev. Sci. Instrum. 2008, 79, 114902. 
(25) Bruns, D.; de Oliveira, T. E.; Rottler, J.; Mukherji, D. Tuning Morphology and Thermal Transport of Asymmetric Smart Polymer Blends by Macromolecular Engineering. Macromolecules 2019, 52, $5510-5517$.

(26) Louette, P.; Bodino, F.; Pireaux, J.-J. Poly(acrylic acid) (PAA). XPS reference core level and energy loss spectra. Surf. Sci. Spectra 2005, 12, 22-26.

(27) Moulder, J. F.; Stickle, W. F.; Sobol, P. E.; Bomben, K. D. Handbook of X-ray Photoelectron Spectroscopy: a Reference Book of Standard Spectra for Identification and Interpretation of XPS Data; Physical Electronics: Eden Prairie, Minnesota, 1995.

(28) Coleman, M. M.; Skrovanek, D. J.; Hu, J.; Painter, P. C. Hydrogen bonding in polymer blends. 1. FTIR studies of urethaneether blends. Macromolecules 1988, 21, 59-65.

(29) Lewis, R. N.; McElhaney, R. N.; Pohle, W.; Mantsch, H. H. Components of the carbonyl stretching band in the infrared spectra of hydrated 1,2-diacylglycerolipid bilayers: a reevaluation. Biophys. J. 1994, 67, 2367-2375.

(30) Irusta, L.; L’Abee, M.; Iruin, J. J.; Fernández-Berridi, M. J. Infrared spectroscopic studies of the urethane/ether inter-association. Vib. Spectrosc. 2001, 27, 183-191.

(31) Xu, Y.; Musgrave, C. B. A DFT Study of the $\mathrm{Al}_{2} \mathrm{O}_{3}$ Atomic Layer Deposition on SAMs: Effect of SAM Termination. Chem. Mater. 2004, 16, 646-653.

(32) Shanker, A.; Li, C.; Kim, G.-H.; Gidley, D.; Pipe, K. P.; Kim, J. High thermal conductivity in electrostatically engineered amorphous polymers. Sci. Adv. 2017, 3, No. e1700342.

(33) Xu, Y.; Wang, X.; Zhou, J.; Song, B.; Jiang, Z.; Lee, E. M.; Huberman, S.; Gleason, K. K.; Chen, G. Molecular engineered conjugated polymer with high thermal conductivity. Sci. Adv. 2018, 4, No. eaar3031.

(34) Shen, X.; Zheng, Q.; Kim, J.-K. Rational design of twodimensional nanofillers for polymer nanocomposites toward multifunctional applications. Prog. Mater. Sci. 2021, 115, 100708.

(35) He, X.; Wang, Y. Recent advances in the rational design of thermal conductive polymer composites. Ind. Eng. Chem. Res. 2021, $60,1137-1154$

(36) Neese, F. Software Update: The ORCA Program System, Version 4.0. Wiley Interdiscip. Rev. Comput. Mol. Sci. 2018, 8, No. e1327.

(37) Weigend, F.; Ahlrichs, R. Balanced Basis Sets of Split Valence, Triple Zeta Valence and Quadruple Zeta Valence Quality for $\mathrm{H}$ to Rn: Design and Assessment of Accuracy. Phys. Chem. Chem. Phys. 2005, 7, 3297.

(38) Lee, C.; Yang, W.; Parr, R. G. Development of the ColleSalvetti Correlation-Energy Formula into a Functional of the Electron Density. Phys. Rev. B: Condens. Matter Mater. Phys. 1988, 37, 785789.

(39) Grimme, S.; Antony, J.; Ehrlich, S.; Krieg, H. A Consistent and Accurate $\mathrm{Ab}$ Initio Parametrization of Density Functional Dispersion Correction (DFT-D) for the 94 Elements H-Pu. J. Chem. Phys. 2010, 132, 154104.

(40) Grimme, S.; Ehrlich, S.; Goerigk, L. Effect of the Damping Function in Dispersion Corrected Density Functional Theory. J. Comput. Chem. 2011, 32, 1456-1465.

(41) Neese, F.; Wennmohs, F.; Hansen, A.; Becker, U. Efficient, Approximate and Parallel Hartree-Fock and Hybrid DFT Calculations. A 'Chain-of-Spheres' Algorithm for the Hartree-Fock Exchange. Chem. Phys. 2009, 356, 98-109. 